\title{
Primary posterior capsular opacification in Indian rural population undergoing cataract surgery for hypermature senile cataract
}

This article was published in the following Dove Press journal:

Clinical Ophthalmology

7 August 2013

Number of times this article has been viewed

\section{Rajesh Subhash Joshi}

Department of Ophthalmology, Vasatrao Naik Government Medical College, Yavatmal, India
Correspondence: Rajesh Subhash Joshi Department of Ophthalmology, Vasatrao Naik Government Medical College, Yavatmal-400000I, India.

Tel+9| 9890 I3I 588

Email jrajesh5@rediffmail.com
Aim: To find out the incidence of primary posterior capsular opacification (PCO) in rural patients with a hypermature senile cataract undergoing cataract surgery.

Settings: Tertiary eye care center in central India.

Design: Prospective, observational, noncomparative study.

Materials and methods: Two-hundred eyes of 200 patients presenting with a hypermature cataract underwent manual small incision cataract surgery. A single surgeon performed all surgeries under peribulbar anesthesia. After cortical clean-up, the capsular bag was inflated with viscoelastic. The presence or absence of opacity on the posterior lens capsule and location was noted. Postoperative follow-up was done for visual acuity and need for neodymium-doped yttrium aluminum garnet (ND:YAG) laser capsulotomy.

Results: Primary PCO occurred in 76 eyes (incidence of 38\%). It was peripheral in 58 eyes (76.3\%) and central in 18 eyes $(23.7 \%)$. At 6 weeks postoperatively, best corrected visual acuity for eyes with central primary PCO $(\mathrm{n}=18)$ was $0.2-0.3 \log \mathrm{MAR}$ and $0-0.2 \log \mathrm{MAR}$ for eyes with peripheral primary PCO $(\mathrm{n}=58)$. Best corrected visual acuity at the 6- and 12-month follow-up was $0-0.2 \log$ MAR in both groups. Fibrotic primary PCO was seen in four patients. No predilection for the development of primary PCO to a particular quadrant of posterior capsule was observed. At 1 year postoperatively, eleven (14.5\%) patients required ND:YAG laser capsulotomy, six (7.90\%) of whom underwent ND:YAG laser capsulotomy at the 6-month follow-up. Seven patients with central primary PCO and four patients with peripheral primary PCO required ND:YAG laser capsulotomy.

Conclusion: A high incidence of primary PCO was noted in rural patients with a hypermature senile cataract undergoing cataract surgery. No serious intraoperative complications were noted. Visual outcome at 1-year follow-up was satisfactory. Need for early ND:YAG laser posterior capsulotomy should be explained to these patients before cataract surgery. No post ND:YAG capsulotomy complications were noted in any patient.

Keywords: posterior capsular opacification, hypermature cataract, manual small incision cataract surgery

\section{Introduction}

Hypermature cataracts constitute a significant proportion of surgical workload in developing countries. ${ }^{1}$ Economic constraints and unequal distribution of eye care facilities in rural populations of developing countries constitute the reasons for late presentation of patients for cataract surgery. ${ }^{2}$ Intraoperative difficulties associated with cataract surgery in hypermature cataracts have been highlighted in various studies. ${ }^{3,4}$

After the cataract is successfully removed, surgeons may come across primary posterior capsule opacification (PCO) of the lens intraoperatively. The location of 
such opacities is variable on the posterior capsule. ${ }^{5}$ These opacities preclude visualization of the retina and could be the cause of suboptimum visual gain immediately after surgery. This opacity is an intrinsic part of the cataract due to late presentation of the patient for cataract surgery. The operating surgeon may have to decide on primary posterior capsulorhexis or early neodymium-doped yttrium aluminum garnet (ND:YAG) laser capsulotomy in these cases.

The present study was done to find out the incidence of primary PCO in an Indian rural population undergoing cataract surgery for hypermature senile cataracts.

\section{Material and methods}

This prospective, observational study included 200 eyes of 200 consecutive patients with hypermature senile cataracts who had a routine manual small incision cataract surgery at Government Medical College and Hospital situated in central India between January 2011 and December 2011. A hypermature cataract was defined as a cataract having a milky cortex or fibrous anterior capsule or both. Preoperative examination included slit lamp biomicroscopy of the anterior segment, intraocular pressure by applanation tonometry, keratometry, and A-scan ultrasonography for intraocular lens power calculation 1 day prior to surgery. B-scan ultrasonography was done for the status of the vitreous and retina. Hypermature cataracts (milky cortex or fibrous anterior capsule or both) without coexisting ocular pathology were included in the study. The preoperative visual acuity of all patients was accurate perception of light and projection of rays. Patients with complicated cataract, pseudoexfoliation, glaucoma, post-vitrectomized eyes, non-dilating pupil, subluxated cataract, only one eye, and no perception of light were excluded from the study.

The ethics committee of the hospital approved the study.

A single surgeon (RSJ) proficient in cataract surgery performed all surgeries as described by Venkatesh et al in their study on white cataracts. ${ }^{6}$ After removal of the nucleus, cortical clean-up was done using a Simcoe irrigation and aspiration cannula (Appasamy Ocular Devices, Puducherry, India). The capsular bag was inflated with viscoelastic. The presence or absence of opacity on the posterior lens capsule and location was noted and charted. Primary PCO was defined as any opacity on the posterior lens capsule that could not be removed by vacuuming or polishing of the posterior capsule lying flat with the posterior capsule. Location of the opacity was charted by the operating surgeon as superotemporal, superonasal, inferotemporal, inferonasal, and central visual axis. Posterior capsular polishing was done with capsular polisher in all cases. Primary posterior capsulorhexis was not performed in any case as ND:YAG laser posterior capsulotomy seemed safer. Any complications that occurred during the intraoperative period were noted. Patients with zonular dehiscence were implanted with an endocapsular ring to stabilize the zonules. Intraocular lens implantation ( $6 \mathrm{~mm}$ optic, $12 \mathrm{~mm}$ overall diameter) in the capsular bag was done. The viscoelastic material was replaced by a balanced salt solution. Stromal hydration of the paracentesis opening was performed. The integrity of the self-sealing scleral incision was insured.

Postoperative follow-up was done at 1 day, 15 days, 45 days, 6 months, and 12 months. The operating surgeon followed up all cases. However, visual status and PCO evaluation was done at 6 weeks, 6 months, and 12 months. Any complaints by the patients were noted. On every postoperative visit, visual acuity, PCO evaluation after dilatation of the pupil under slit lamp, and need for posterior capsulotomy were evaluated. The data was entered in an Excel ${ }^{\circledR}$ sheet (Software version 14.1.0 [110310] 2011) (Microsoft Corporation, Redmond, WA, USA) and statistical analysis performed with SPSS version 13.0 (SPSS Inc, Chicago, IL, USA) after 1 year.

\section{Results}

The average age of the study group was $66.37 \pm 14.3$ years and included 106 females and 94 males. Primary PCO occurred in 76 eyes (incidence of 38\%). It was peripheral in 58 eyes $(76.3 \%)$ and central in 18 eyes (23.7\%). At 6 weeks postoperatively, eyes with central primary PCO $(n=18)$ had best corrected visual acuity (BCVA) of 0.2-0.3 LogMAR. Eyes with peripheral primary PCO $(n=58)$ had BCVA of $0-0.2$ LogMAR. BCVA at the 6- and 12-month follow-up was 0-0.2 LogMAR in both groups after ND:YAG capsulotomy. BCVA of the remaining patients (ie, those without primary PCO; $\mathrm{n}=124)$ was stable at each follow-up (0-0.2 LogMAR). The distribution of primary PCO in different areas of the posterior capsule is presented in Table 1. Fibrotic primary

Table I Distribution of primary posterior capsular opacification in different areas of the posterior capsule

\begin{tabular}{ll}
\hline Areas of posterior capsule & Number of eyes \\
\hline Central & 18 \\
Inferonasal & 15 \\
Inferotemporal & 14 \\
Superotemporal & 13 \\
Superonasal & 16 \\
Total & 76 \\
\hline
\end{tabular}


PCO was seen in four patients on the peripheral side of the posterior capsule.

Capsulorhexis extension occurred in three patients. Angled capsulotomy scissors were used to cut the fibrotic capsule and capsulorhexis forceps were used to complete the capsulorhexis.

Two patients had zonular dehiscence during removal of the nucleus from the capsular bag. An endocapsular ring was implanted in the capsular bag to stabilize the zonules.

At 1 year postoperatively, eleven (14.5\%) patients required ND:YAG laser capsulotomy, six (7.90\%) of whom underwent ND:YAG laser capsulotomy at the 6-month follow-up.

\section{Discussion}

Mature cataracts constitute a major surgical workload in developing countries. ${ }^{6}$ Due to socioeconomic constraints and unequal distribution of eye care services in rural populations, patients present late for cataract surgery. Difficulties associated with managing hypermature and mature cataracts have been highlighted in various studies. ${ }^{3,4}$ Visual rehabilitation after cataract surgery is important. The presence of primary $\mathrm{PCO}$ in these cases may affect postoperative visual outcome. It can create dissatisfaction amongst patients undergoing cataract surgery. The surgeon may have to consider early ND:YAG laser capsulotomy or needling of the thick fibrotic posterior capsule through the pars plana.

Implanting hydrophobic or square-edged intraocular ${ }^{7}$ lenses can prevent PCO. ${ }^{8}$ However, primary PCO occurring in patients with a hypermature cataract can only be prevented by early removal of cataractous lenses before it reaches the stage of maturity.

The present study was done on patients with a hypermature senile cataract from the rural population of the Vidharbha region of eastern Maharashtra, India. The total population of the district is $2,775,457$. The majority of them stay in the rural area (rural 2,176,252; urban 599,205). ${ }^{9}$

The incidence of primary PCO in this study was 38\%, which was higher than that reported in Vasavada et al's study on mature cataracts. ${ }^{5}$ The high incidence could be due to the inclusion of patients with a hypermature cataract only. Anterior capsular opacity is also reported in eyes with a hypermature cataract.

The majority of patients had involvement of the peripheral part of the posterior capsule $(76.3 \%)$ as compared to the central area $(23.7 \%)$. The posterior capsule is usually free of lens epithelial cells. The lens epithelial cells from the equatorial area proliferate on the posterior capsule and form PCO. Some of them stop at the peripheral part of the posterior capsule leading to peripheral primary PCO, while some enter the visual axis causing central primary PCO. Lens epithelial cells transform into myofibroblasts causing white fibrotic opacification. ${ }^{10}$ Fibrotic primary PCO was seen in four patients on the peripheral part of the posterior capsule, but did not affect visual acuity.

Peripheral primary PCO was divided into four areas of the posterior capsule depending upon the presence of opacity. There was no predilection to a particular quadrant for the development of primary PCO. Involvement of the inferotemporal quadrant of the posterior capsule was found in Ashraf's study on the distribution of primary PCO in hypermature cataracts. ${ }^{11}$ At 1 year postoperatively, three patients with peripheral primary PCO had opacification of the central part of the posterior capsule. However, there was no continuity between peripheral primary $\mathrm{PCO}$ and the newly formed central PCO.

This study was done on patients with a hypermature cataract. Intraoperative complications - related to the fibrotic anterior capsule and weak zonular apparatus - do occur in these patients. There is a tendency for capsulorhexis extension towards the periphery. Sometimes, dislocation of the entire capsular bag may occur while performing capsulotomy. Capsulorhexis extension occurred in three cases. However, no extension of the anterior capsular tear was seen on the posterior capsule. An angular cut to the advancing edge of the anterior capsule can avoid this complication.

Zonular dehiscence can occur during the removal of the nucleus from the capsular bag. Two patients had zonular dehiscence. Placement of an endocapsular ring in the capsular bag helped to stabilize the weakened zonular apparatus. The intraocular lens was placed in the capsular bag after confirming integrity of the capsular bag. No serious intraoperative complications occurred (nucleus drop and vitreous loss) during the study period.

This study included patients living in a rural area. These patients may not have high visual demand. They did not complain of blurring of vision or glare at night during the initial follow-up period. BCVA at 6 weeks was better in patients with peripheral primary PCO than central primary PCO. However, BCVA at 6 months and 12 months was almost equal (0-0.2 LogMAR) in both groups after performing ND:YAG capsulotomy. There was definite improvement in visual acuity - accurate perception of light and projection of rays - at the 12-month follow-up.

Eleven patients required ND:YAG laser posterior capsulotomy at the 1-year follow-up, six of whom underwent 
ND:YAG laser capsulotomy at 6 months. No patients developed post ND:YAG capsulotomy complications, proving safety in these patients.

Primary posterior capsulorhexis has been advocated to remove primary $\mathrm{PCO}^{12}$ and to prevent PCO.$^{13}$ Primary posterior capsulorhexis was not performed in this study as posterior segment complications are higher if the posterior capsule is breached. ${ }^{14}$ Vitreous herniation and entanglement has been reported by Menapace. ${ }^{15}$ The closure of primary posterior capsulorhexis has been noted in various studies. ${ }^{14,16}$

\section{Conclusion}

The present study shows a high incidence of primary PCO in rural patients with a hypermature senile cataract undergoing cataract surgery. Intraoperative complications should be anticipated while operating on these patients. The need for early ND:YAG capsulotomy should be explained to the patient to avoid dissatisfaction. Visual outcome at the 1-year follow-up was satisfactory.

\section{Disclosure}

The author reports no conflicts of interest in this work.

\section{References}

1. Venkatesh R, Tan CS, Sengupta S, Ravindran RD, Krishnan KT, Chang DF. Phacoemulsification versus manual small-incision cataract surgery for white cataract. J Cataract Refract Surg. 2010;36(11): $1849-1854$.

2. Khanna R, Pujari S, Sangwan V. Cataract surgery in developing countries. Curr Opin Ophthalmol. 2011;22(1):10-14.
3. Kothari K, Jain SS, Shah NJ. Anterior capsular staining with trypan blue for capsulorhexis in mature and hypermature cataracts. A preliminary study. Indian J Ophthalmol. 2001;49(3):177-180.

4. Vasavada A, Singh R, Desai J. Phacoemulsification of white mature cataracts. J Cataract Refract Surg. 1998;24(2):270-277.

5. Vasavada AR, Chauhan $H$, Shah $G$. Incidence of posterior capsular plaque in cataract surgery. $J$ Cataract Refract Surg. 1997;23(5):798-802.

6. Venkatesh R, Das M, Prashanth S, Muralikrishnan R. Manual small incision cataract surgery in eyes with white cataracts. Indian $J$ Ophthalmol. 2005;53(3):173-176.

7. Hazra S, Palui H, Vemuganti GK. Comparison of design of intraocular lens versus the material for PCO prevention. Int J Ophthalmol. 2012;5(1):59-63.

8. Johansson B. Clinical consequences of acrylic intraocular lens material and design: Nd:YAG-laser capsulotomy rates in $3 \times 300$ eyes 5 years after phacoemulsification. Br J Ophthalmol. 2010;94(4):450-455.

9. Available from: http://www.censusindia.net/. Accessed May 2, 2013.

10. Kappelhof JP, Vrensen GF. The pathology of after-cataract: a minireview. Acta Ophthalmol Suppl. 1992;(205):13-24.

11. Ashraf KM. Primary posterior capsular opacification in hypermature white cataracts. $J$ Cataract Refract Surg. 2010;36(12):2211-2212.

12. Yazici AT, Bozkurt E, Kara N, Yildirim Y, Demirok A, Yilmaz OF. Long-term results of phacoemulsification combined with primary posterior curvilinear capsulorhexis in adults. Middle East Afr $J$ Ophthalmol. 2012;19(1):115-119.

13. Galand A, van Cauwenberge F, Moosavi J. Posterior capsulorhexis in adult eyes with intact and clear capsules. $J$ Cataract Refract Surg. 1996;22(4):458-461.

14. van Cauwenberge F, Rakic JM, Galand A. Complicated posterior capsulorhexis: aetiology, management, and outcome. Br J Ophthalmol. 1997;81(3): 195-198.

15. Menapace R. Posterior capsulorhexis combined with optic buttonholing: an alternative to standard in-the-bag implantation of sharp-edged intraocular lenses? A critical analysis of 1,000 consecutive cases. Graefes Arch Clin Exp Ophthalmol. 2008;246(6):787-801.

16. De Groot V, Vrensen GF, Willekens B, Van Tenten Y, Tassignon MJ. In vitro study on the closure of posterior capsulorhexis in the human eye. Invest Ophthalmol Vis Sci. 2003;44(5):2076-2083.
Clinical Ophthalmology

\section{Publish your work in this journal}

Clinical Ophthalmology is an international, peer-reviewed journal covering all subspecialties within ophthalmology. Key topics include: Optometry; Visual science; Pharmacology and drug therapy in eye diseases; Basic Sciences; Primary and Secondary eye care; Patient Safety and Quality of Care Improvements. This journal is indexed on

\section{Dovepress}

PubMed Central and CAS, and is the official journal of The Society of Clinical Ophthalmology (SCO). The manuscript management system is completely online and includes a very quick and fair peer-review system, which is all easy to use. Visit http://www.dovepress.com/ testimonials.php to read real quotes from published authors. 